\title{
Barreiras e oportunidades para a implementação dos princípios de IPD e práticas de LPDS na gestão dos projetos de instalações da indústria de base brasileira
}

\author{
Barriers and opportunities for the implementation of IPD \\ principles and LPDS practices in the management of \\ capital industrial projects in Brazil
}

\begin{abstract}
Vinícius loppi
Carlos Torres Formoso

Eduardo Luis Isatto

Resumo

A

abordagem tradicional de gestão de projetos desconsidera a natureza dos projetos de construção atuais, e a teoria implícita que fundamenta esta abordagem tem sido apontada como obsoleta. Além disso, projetos com diferentes características são gerenciados da mesma forma, independentemente do nível de complexidade envolvida. Como consequência disto, muitos projetos não têm atingido seus objetivos, principalmente os de natureza complexa. O presente trabalho propõe um modelo de implantação gradual de um Sistema de Gestão de Projeto (SGP) baseado nos princípios de Integrated Project Delivery (IPD) e práticas de Lean Project Delivery System (LPDS) para o contexto dos projetos de instalações da indústria de base. O método de pesquisa envolveu a realização de um estudo inicial numa indústria de base, seguido da realização de entrevistas com agentes chaves do segmento de projetos de instalações da indústria de base. Por fim, foram realizados dois estudos de caso breves em projetos já concluídos. As principais contribuições do estudo foram a identificação das principais barreiras e oportunidades para a implementação do SGP proposto no contexto atual brasileiro e a proposição de um modelo para a sua implantação gradual.

Palavras-chave: Gestão de projetos. Integrated Project Delivery. Lean Project Delivery System. Sistema de gestão de projeto.

Vinícius loppi Gerdau Riograndense Sapucaia do Sul - RS - Brasil

Carlos Torres Formoso Universidade Federal do Rio Grande do Sul Porto Alegre - RS - Brasil

Eduardo Luis Isatto Universidade Federal do Rio Grande Porto Alegre - RS - Brasil

Abstract

Traditional project management approaches do not consider properly the current nature of construction projects, and the underlying theory has been considered obsolete. Moreover, projects with different characteristics are managed in the same way, regardless of the degree of complexity involved. Consequently, many projects do not achieve their goals, especially the most complex ones. This study proposes a model for gradual implementation of a Project Delivery System (PDS) based on Integrated Project Delivery (IPD) principles and Lean Project Delivery System (LPDS) practices in the context of capital industrial projects. The research method involved an initial case study in a project carried out by an industrial client, followed by interviews with key stakeholders from the capital industrial building market segment. Finally, two brief case studies on past projects were carried out. The main contributions of this study is the identification of barriers and opportunities to the implementation of the proposed SGP in the current context in Brazil, and as well as a model for the gradual implementation of that system.
\end{abstract}

Recebido em 23/02/15 Aceito em 14/07/15
Keywords: Project management. Integrated Project Delivery. Lean Project Delivery System, Project Delivery System.

IOPPI, V.; FORMOSO, C. T.; ISATTO, E. L. Barreiras e oportunidades para a implementação dos princípios de IPD e práticas de LPDS na gestão dos projetos de instalações da indústria de base brasileira. Ambiente Construído, Porto Alegre,v. 15, n. 4, p. 87-104, out./dez. 2015. 


\section{Introdução}

O presente estudo aborda a gestão dos projetos $^{1}$ de instalações da indústria de base, definidos como aqueles que envolvem a concepção, construção e montagem de instalações e equipamentos necessários para o atingimento dos objetivos do empreendimento. Nesse contexto, há relatos de que as organizações têm enfrentado dificuldades para implementar seus projetos e usufruir de seus benefícios (DINSMORE; MUTTI; ROCHA, 2011).

Há indicações que tais problemas estão relacionados à inadequação da abordagem tradicional de gestão de projetos, a qual não considera apropriadamente a natureza complexa dos projetos (WILLIAMS, 2002). Atkinson, Crawford e Ward (2006) afirmam que no contexto atual os projetos não podem ser considerados como uma progressão linear de atividades para atingir objetivos preestabelecidos, sendo inadequado o modelo de gestão conhecido como management-as-planning, no qual a gestão consiste na elaboração de planos detalhados e a busca pela aderência das atividades realizadas a esses planos, ou seja, assume-se que os planos inicialmente definidos são simplesmente transformados em ações (KOSKELA; HOWELL, 2002). Além disso, Winter et al. (2006) destacam que na abordagem tradicional negligenciam-se as interações sociais entre as pessoas, os interesses distintos entre os agentes e as pressões políticas e sociais.

Além disso, Koskela e Howell (2002) destacam que a abordagem tradicional de gestão de projetos carece de uma fundamentação teórica mais profunda. Algumas das práticas dessa abordagem podem ser consideradas como obsoletas, tais como o controle centralizado e a lógica de que a otimização das partes resulta na otimização do projeto como um todo (HOWELL; MESA; ALARCÓN, 2013). Outro ponto que tem sido alvo de discussões é o fato de a abordagem tradicional considerar as etapas do projeto de forma sequencial, ou seja, cada etapa é tratada em separado e de forma isolada (HOWELL; MESA; ALARCÓN, 2013). Devido a isso, uma série de retrabalhos são gerados; por exemplo, durante a etapa de construção são verificadas diversas dificuldades para execução relacionadas à falta de construtibilidade do design ${ }^{2}$ (BALLARD, 2012; KOSKELA; HOWELL, 2002).

\footnotetext{
${ }^{1}$ A expressão gestão de projetos é usada no presente trabalho como sinônimo de gestão de empreendimentos (project management).

${ }^{2} \mathrm{O}$ termo design se refere aqui a projetos de engenharia e arquitetura.
}

Em relação aos tipos de contratos adotados, eles usualmente são de caráter transacional e, em vez de focar na maximização dos resultados do projeto e criar um ambiente colaborativo entre os agentes envolvidos, buscam criar uma proteção legal do cliente, devido à falta de confiança entre as partes (SAKAL, 2005). Nesse tipo de contrato alguns intervenientes, tais como a empresa construtora e os subempreiteiros, são envolvidos tardiamente, após a conclusão do projeto detalhado. Como consequência são geradas divergências entre o executor e o cliente, expressas através de pleitos (DELOITTE, 2013), ou seja, demandas por parte do executor para que o contrato seja aditado de modo a incluir em seu objeto determinados serviços adicionais ou, ainda, para que o cronograma da obra seja estendido para contemplar serviços adicionais ou atrasos, e para evitar aplicação de multas (BAPTISTA et al., 2010).

Em contraposição às práticas tradicionais de gestão de projetos, um leque de novas abordagens tem surgido nos últimos anos, as quais enfatizam a colaboração entre os diferentes intervenientes dos projetos. Merece destaque a abordagem conhecida como Integrated Project Delivery (IPD), com crescente disseminação nos EUA, que prescreve o alinhamento de interesses comerciais, uma estrutura integrada de tomada de decisão e um conjunto de princípios gerenciais. Merece destaque também a aplicação de conceitos e princípios da produção enxuta à gestão de projetos, conhecida como Lean Project Delivery System (LPDS), pelos resultados positivos alcançados em alguns empreendimentos (SMITH; MOSSMAN; EMMITT, 2011).

O presente estudo tem como objetivo identificar as principais barreiras e oportunidades para a utilização de uma nova abordagem para a gestão dos projetos de instalações da indústria de base, baseada nos princípios de IPD e práticas de LPDS. Além disso, esta pesquisa propõe o desenvolvimento de um modelo de implantação gradual da abordagem proposta no contexto atual do Brasil.

\section{Sistema de Gestão de Projetos}

No presente trabalho adota-se uma definição ampla de Sistema de Gestão de Projetos (SGP), referente à forma de organizar o projeto, de definir as relações e interações entre os agentes e de alocar e compartilhar os riscos e benefícios do projeto, de maneira similar à definição da The American Institute of Architects (AMERICAN..., 2007). Não 
se restringe ao sistema de gestão de projetos da empresa executora, correspondendo ao que é normalmente conhecido na literatura internacional como Project Delivery System. Assim, faz-se uma distinção entre o SGP como um todo e alguns de seus componentes, que têm sido objeto de estudos específicos, definidos a seguir (AUSTROADS, 2014; SCHMITT, 2006; JOHANNSEN, 2013):

(a) Forma de Contratação (FC): corresponde à forma como o projeto é executado do ponto de vista de abrangência do escopo de execução, número de partes envolvidas e respectivas interações entre si, e de definição das responsabilidades entre os agentes-chave do projeto; e

(b) Instrumento Contratual (IC): uma consequência da forma de contratação adotada, está relacionado à forma do contrato, mecanismo de remuneração e alocação de riscos entre as partes.

As formas de contratação mais frequentemente utilizadas nos projetos de instalações no Brasil são do tipo Construção (Design - Bid - Build - DBB), Engenharia e Construção (Design and Build DB), Engenharia, Suprimento e Construção (Engineering, Procurement and Construction EPC), Aliança (Alliance) e Gerenciamento de Projetos (Project Management) (RICARDINO, 2007).

Em relação aos contratos, podem ser categorizados em três tipos (WILLIAMSON, 1985): contrato clássico, contrato neoclássico e contrato relacional. A diferença entre os três tipos de contratos está basicamente relacionada à duração do contrato, à frequência e à forma como as partes se relacionam. Ross e PCI Alliance Services (2009) afirma que os contratos relacionais são mais adequados a projetos complexos por seu elevado grau de incerteza e pela elevada velocidade de concepção e implantação, conforme indicado na Figura 1. O principal componente do contrato relacional é o estabelecimento das relações de trabalho mutuamente desenvolvidas entre as partes, através de uma estratégia formal de compromissos e comunicação que visa ao estabelecimento de relações ganha-ganha entre as partes (CHAN; CHAN; YEUNG, 2010).

\section{Integrated Project Delivery}

AIA define IPD como
[...] uma abordagem de gerenciamento de projetos que integra pessoas, sistemas, estruturas de negócios e práticas num processo que aproveita talentos e percepções de todos os participantes do projeto de forma colaborativa a fim de otimizar os resultados do projeto, incrementar valor para o proprietário, reduzir perdas e maximizar a eficácia através de todas as fases do design, fabricação e construção [...]" (AMERICAN..., 2007).

Segundo Ghassemi e Becerik-Gerber (2011), a aplicação de IPD requer um ambiente baseado em relações de confiança entre os agentes, colaboração, integridade e transparência, respeito mútuo, comprometimento e abertura para o aprendizado contínuo.

Figura 1 - Comparação da conveniência entre contratos tradicionais e relacionais em função das circunstâncias do projeto

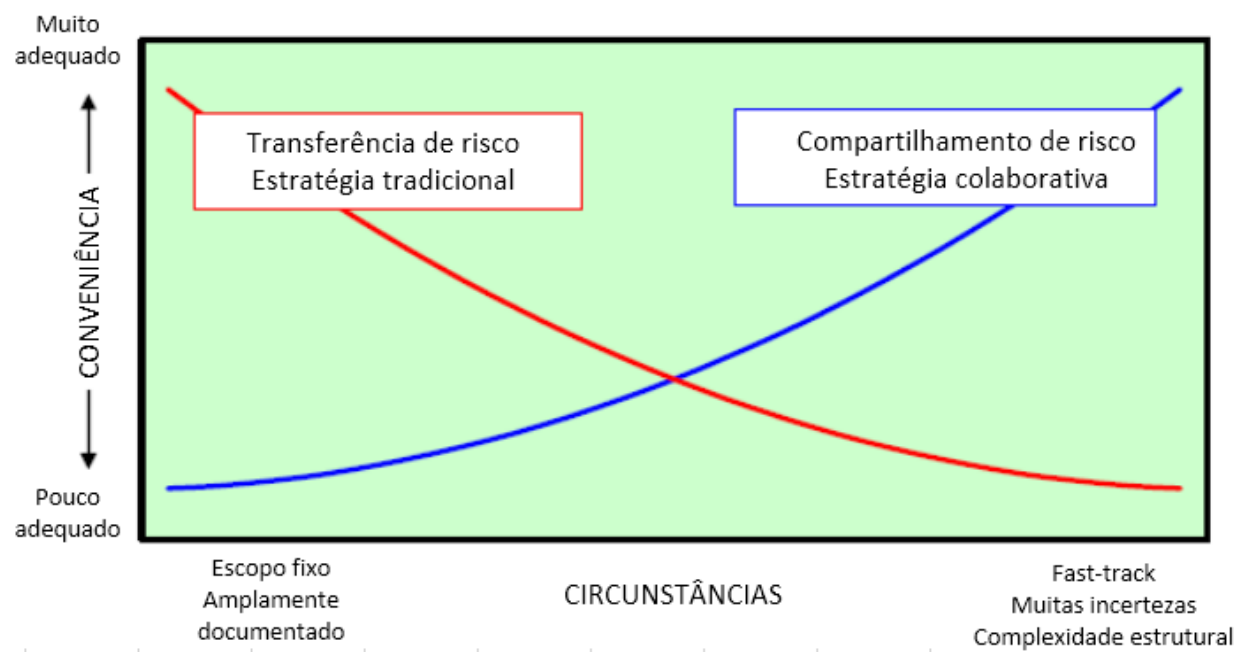

Fonte: adaptado de Ross e PCI Alliance Services (2009). 
Existem outras definições de IPD na literatura, mas existe uma série de princípios comuns a várias definições, que foram utilizados neste estudo para caracterizar a nova abordagem para gestão dos projetos de instalações industriais (AMERICAN..., 2007; THOMSEN et al., 2009):

(a) envolvimento dos agentes desde cedo: envolver os principais representantes do cliente, projetista, executores e fornecedores desde a concepção do projeto;

(b) governança integrada: coordenação do projeto realizada por meio de um core group, ${ }^{3}$ com representantes dos agentes-chave do projeto;

(c) tomada de decisão compartilhada: as decisões são tomadas de forma conjunta por meio do core group, com base em informações geradas pelas equipes multidisciplinares;

(d) inovação colaborativa: por meio do trabalho em equipe e do compartilhamento de riscos e benefícios, busca-se incentivar a inovação ao longo de todo o projeto; e

(e) definição de metas comuns: estabelecer metas comuns aos agentes, de modo a incentivar a busca por melhores soluções de design, a fim de cumprir os propósitos do projeto e agregar mais valor a ele.

\section{Lean Project Delivery System}

A Filosofia Lean também tem sido aplicada no contexto da gestão de projetos. Segundo Koskela e Ballard (2006), a fundamentação teórica da gestão de produção pode ser utilizada no contexto da gestão dos projetos, sendo nesta visão os projetos entendidos como um sistema de produção temporário. Além dos princípios de IPD, que fazem parte de LPDS, destacam-se duas práticas adotadas com sucesso em distintos projetos: Target Value Design (TVD) e Set Based Design.

$\mathrm{O}_{\mathrm{TVD}}^{4}$ é uma adaptação da abordagem de Target Costing ${ }^{5}$ (TC), utilizada na indústria da manufatura, para os projetos da construção (BALLARD, 2012). Originalmente, TC foi utilizado com o objetivo de reduzir o custo final do produto, para garantir a lucratividade esperada e,

\footnotetext{
${ }^{3}$ Grupo central.

${ }^{4}$ Target Value Design pode ser traduzido como o valor-meta para o design no sentido da geração de valor tanto para os agentes intervenientes quanto para o próprio produto do projeto.

${ }^{5}$ Target Costing pode ser entendido como um sistema de custeio que estabelece o custo-meta que um produto com determinada qualidade pode ser produzido, a fim de definir o nível desejado de lucratividade, tendo em vista o preço pré-fixado de venda no mercado (COOPER; SLAGMULDER, 1997). O custo-meta abordado nesta pesquisa é o mesmo proposto por Ballard (2008), sendo entendido como o custo situado abaixo do custo permissível, o qual representa a disponibilidade orçamentária do projeto.
}

ao mesmo tempo, níveis satisfatórios de qualidade através da engenharia de valor (COOPER, 1995). Segundo Smith, Mossmann e Emmitt (2011), TVD, no contexto de projetos complexos, incentiva a inovação e a criatividade, pois a partir de um custo-meta o design deve ser desenvolvido levando-se em consideração os propósitos do projeto, o orçamento disponível, o desempenho em uso, entre outros fatores. O custo-meta abordado nesta pesquisa é o mesmo proposto por Ballard (2008), no qual é entendido como o custo situado abaixo do custo permissível, que representa a disponibilidade orçamentária do projeto.

Set Based Design, por sua vez, representa uma alternativa em relação às práticas tradicionais de design, tais como a engenharia simultânea ponto a ponto (point-based), as quais partem de um único conceito (suposta melhor alternativa de design) e, por meio de um processo iterativo, refinam essa alternativa até chegar a uma solução viável, em que se tenham conseguido as características desejadas pelo mercado, ou seja, um ponto na gama de possíveis soluções (WARD; LIKER; SOBEK, 1999; YU; CAMARGO JUNIOR, 2007). A partir disso, a solução é detalhada, buscando atender aos objetivos do design.

\section{Método de pesquisa}

O presente estudo enquadra-se no modo de produção do conhecimento denominado design science research, também conhecido como ciências do design. A pesquisa foi dividida em cinco etapas conforme representado na Figura 2.

Na etapa de concepção foi definido o escopo da pesquisa, sendo a motivação inicial do estudo relacionada ao fato de um dos autores, na ocasião, trabalhar numa indústria de base, denominada de empresa ALFA, especificamente na gestão de projetos de instalações.

O estudo inicial teve como objetivo o levantamento de informações sobre as práticas vigentes na gestão de projetos de instalações industriais, observando seu contexto, principais características, fragilidades e oportunidades. Com base nisso foi possível caracterizar o patamar atual de práticas de gestão de projetos no contexto estudado, o qual foi utilizado como referência para a definição de um modelo de transição gradativo desse contexto para uma nova abordagem na gestão de projetos. 
Figura 2 - Delineamento da pesquisa

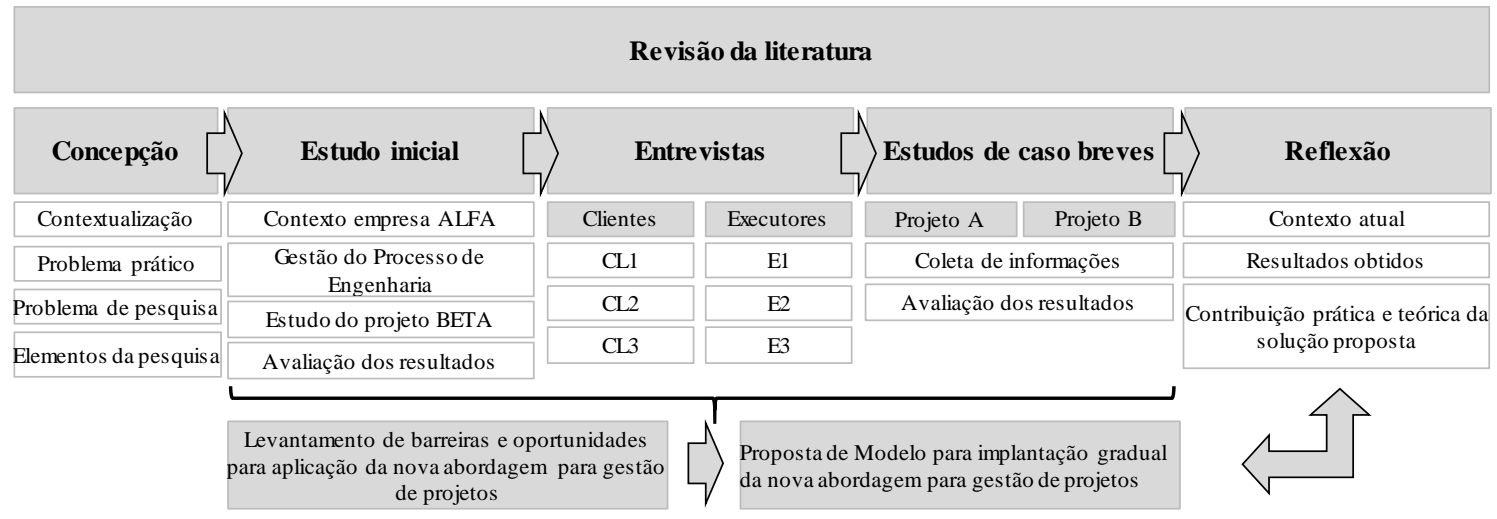

O estudo foi realizado na área responsável pela gestão de projetos da empresa ALFA. Inicialmente foi caracterizado o processo de gestão de projetos dessa empresa e, em seguida, foi realizado o estudo de um projeto em andamento, denominado de projeto BETA, no qual foram acompanhados dois processos de contratação ${ }^{6}$ dos seguintes pacotes de trabalhos: movimentação de terra (EC1); e obras civis juntamente com estruturas metálicas (EC2). Neste estudo buscou-se introduzir no processo de contratação da empresa ALFA algumas práticas relacionadas aos princípios de IPD, tais como o envolvimento dos principais agentes desde o início do projeto, tomada de decisão compartilhada e inovação colaborativa. Não foram incorporados os princípios de governança integrada e definição de metas comuns devido a limitações do processo licitatório estudado.

Ao final dos EC1 e EC2 foi realizada uma avaliação do nível de aderência (NA) das empresas participantes dos processos em relação às práticas aplicadas. Os critérios de avaliação do NA para cada princípio de IPD e respectivas fontes de evidência utilizadas são apresentados no Quadro 1. Foi estabelecida a seguinte escala para definição do NA:

(a) 1 (um): NA baixo, ou seja, a proponente não teve aderência ao aspecto específico;

(b) 3 (três): NA médio, ou seja, a proponente atendeu de forma parcial ao aspecto proposto; e

(c) 5 (cinco): NA alto, ou seja, a proponente atendeu de forma satisfatória ao aspecto proposto.

Após a conclusão dos EC1 e EC2, a empresa ALFA decidiu não efetivar as contratações nos moldes estudados, mas optou pelo processo de contratação tradicional. Com isso, o estudo inicial englobou apenas o acompanhamento e avaliação

\footnotetext{
${ }^{6}$ Também conhecido como processo licitatório.
}

dos processos de contratação, e não a execução dos pacotes de trabalho, cujo estudo estava inicialmente planejado na pesquisa. Dessa forma, o planejamento da pesquisa foi alterado, optando-se por complementar o estudo inicial com entrevistas e estudos de caso breves em outros projetos.

$\mathrm{Na}$ etapa de entrevistas buscou-se coletar informações relacionadas às práticas de gestão de projetos vigentes do ponto de vista de clientes e executores. Os critérios utilizados para seleção dos setores e empresas para a realização das entrevistas consideraram a importância econômica do setor, a previsão de investimentos futuros e a experiência das empresas executoras. Com base nesses critérios foram escolhidos e entrevistados representantes das indústrias siderúrgica (CL1), petrolífera (CL2) e petroquímica (CL3) por parte dos clientes e representantes de empresas executoras de estruturas metálicas (E1), terraplenagem e pavimentação (E2) e construção civil (E3). As entrevistas foram do tipo semiestruturadas, com análise de seus conteúdos. Os perfis dos entrevistados estão apresentados no Quadro 2.

Com base nas entrevistas foram escolhidos dois estudos de caso breves, realizados nos projetos $\mathrm{A}$ e B, nos quais foram analisados os sistemas de gestão de projetos e seus desempenhos, incluindo a abordagem comercial utilizada, modelo de gestão da equipe, resultados obtidos, entre outros. O principal motivo para escolha do Projeto A foi a dinâmica utilizada na gestão do projeto e a forma de relacionamento entre as partes, cliente e executoras, representativa da abordagem tradicional na gestão de projetos. Esses aspectos foram levantados durante a realização da entrevista com E1. Já o Projeto B, apesar de não ser uma obra industrial, foi estudado devido à aplicação de uma abordagem diferenciada em relação ao compartilhamento de riscos e benefícios entre cliente e executora, levantada durante a entrevista com E2. 
Quadro 1 - Princípios, aspectos, critérios de avaliação para determinação do NA da proponente ao processo proposto e fontes de evidência utilizadas

\begin{tabular}{|c|c|c|c|}
\hline Princípios & Aspectos & Critérios de avaliação das empreiteiras & Fontes de evidência \\
\hline \multirow{4}{*}{$\begin{array}{l}\text { Envolver agentes chave desde o } \\
\text { início }\end{array}$} & $\begin{array}{l}\text { Colaboração entre as } \\
\text { partes }\end{array}$ & $\begin{array}{l}\text { Proatividade; Compartilhamento de recursos e } \\
\text { experiências anteriores }\end{array}$ & $\begin{array}{l}\text { Atas de reuniões, } \\
\text { Notas do pesquisador }\end{array}$ \\
\hline & Participação & $\begin{array}{l}\text { Presença nas reuniões; Disponibilização de recursos } \\
\text { humanos; Contatos com o cliente }\end{array}$ & $\begin{array}{l}\text { Atas de reuniões, E- } \\
\text { mails }\end{array}$ \\
\hline & Alinhamento & $\begin{array}{l}\text { Entendimento do processo proposto; Adequação da } \\
\text { empresa para participação }\end{array}$ & $\begin{array}{l}\text { E-mails, Carta de } \\
\text { manifestação de } \\
\text { interesse }\end{array}$ \\
\hline & Engajamento & $\begin{array}{l}\text { Atendimento às demandas do projeto; Disponibilização } \\
\text { de recursos humanos }\end{array}$ & $\begin{array}{l}\text { Atas de reuniões, E- } \\
\text { mails, Notas do } \\
\text { pesquisador }\end{array}$ \\
\hline $\begin{array}{l}\text { Tomada de decisão } \\
\text { compartilhada }\end{array}$ & Soluções de design & $\begin{array}{l}\text { Discussão conjunta do design; Compartilhamento de } \\
\text { experiências anteriores }\end{array}$ & $\begin{array}{l}\text { Proposta técnica, E- } \\
\text { mails, Atas de reuniões }\end{array}$ \\
\hline \multirow[t]{2}{*}{ Inovação colaborativa } & Otimização do design & Proposição de soluções inovadoras de design & Proposta técnica \\
\hline & $\begin{array}{l}\text { Compartilhamento de } \\
\text { experiências }\end{array}$ & $\begin{array}{l}\text { Discussão conjunta do design; Compartilhamento de } \\
\text { experiências anteriores }\end{array}$ & $\begin{array}{l}\text { Atas de reuniões, } \\
\text { Notas do pesquisador }\end{array}$ \\
\hline
\end{tabular}

Quadro 2 - Perfil dos entrevistados

\begin{tabular}{|c|c|c|c|c|c|c|}
\hline & \multicolumn{3}{|c|}{ Representantes Clientes } & \multicolumn{3}{|c|}{ Representantes empresas Executoras } \\
\hline & CL1 & CL2 & CL3 & E1 & \begin{tabular}{|c|}
$\mathrm{E} 2$ \\
\end{tabular} & E3 \\
\hline $\begin{array}{l}\text { Experiência } \\
\text { profissional }\end{array}$ & $>25$ anos & $>5$ anos & $>20$ anos & $>15$ anos & $>25$ anos & $>5$ anos \\
\hline $\begin{array}{c}\text { Tipos de } \\
\text { projetos de que } \\
\text { já participou ou } \\
\text { participa }\end{array}$ & $\begin{array}{c}\text { Industriais - } \\
\text { siderurgia, } \\
\text { mineração }\end{array}$ & $\begin{array}{c}\text { Industriais - óleo e } \\
\text { gás }\end{array}$ & $\begin{array}{l}\text { Industriais - } \\
\text { siderurgia e } \\
\text { petroquímica }\end{array}$ & $\begin{array}{c}\text { Industriais - siderurgia, } \\
\text { cimenteira, automotiva, } \\
\text { naval, fertilizantes, } \\
\text { bebidas, alimentos) }\end{array}$ & $\begin{array}{c}\text { Industriais (siderurgia, } \\
\text { cimenteira, } \\
\text { automotiva); } \\
\text { Varejo (shoppings); } \\
\text { Infraestrutura urbana } \\
\text { (saneamento, } \\
\text { estradas) }\end{array}$ & $\begin{array}{c}\text { Industriais } \\
\text { (siderurgia, } \\
\text { cimenteira); } \\
\text { Infraestrutura } \\
\text { pesada } \\
\text { (barragens, } \\
\text { estradas, } \\
\text { saneamento) }\end{array}$ \\
\hline Função & Controller & $\begin{array}{l}\text { Engenheiro de } \\
\text { processo }\end{array}$ & $\begin{array}{c}\text { Coordenador } \\
\text { de projetos }\end{array}$ & $\begin{array}{c}\text { Gestor de contratos e } \\
\text { montagens }\end{array}$ & $\begin{array}{c}\text { Coordenador de } \\
\text { obras }\end{array}$ & $\begin{array}{c}\text { Gerente de } \\
\text { contratos }\end{array}$ \\
\hline
\end{tabular}

Com base nas informações levantadas nas etapas anteriores foi realizada uma etapa de reflexão sobre o contexto e práticas vigentes na gestão dos projetos de instalações. A partir disso foram identificadas as principais barreiras e oportunidades para a aplicação de uma nova abordagem na gestão dos projetos de instalações. A proposta de modelo para implantação gradual do SGP explorado emergiu ao longo do estudo, e dessa forma sua avaliação não fez parte do escopo da pesquisa.

\section{Caracterização dos estudos}

A empresa ALFA é uma indústria siderúrgica de grande porte. O projeto BETA, foco do primeiro estudo, tinha como principal objetivo ampliar a capacidade de produção de aço dela. Para tanto, o escopo do projeto contemplava a construção de uma nova área de produção na planta (Figura 3), desativando a instalação atual. $\mathrm{O}$ investimento total previsto era da ordem de US\$ 220 milhões.

$\mathrm{O}$ projeto A correspondia à construção de um prédio industrial para um estaleiro (Figura 4).

$\mathrm{O}$ projeto $\mathrm{B}$ era relativo à duplicação de uma avenida em Porto Alegre/RS (Figura 5), necessária devido à construção de um shopping. $O$ valor proposto para a obra foi de $\mathrm{R} \$ 7,37$ milhões. 
Figura 3 - Vistas 3D das novas instalações para produção de aço - Projeto BETA

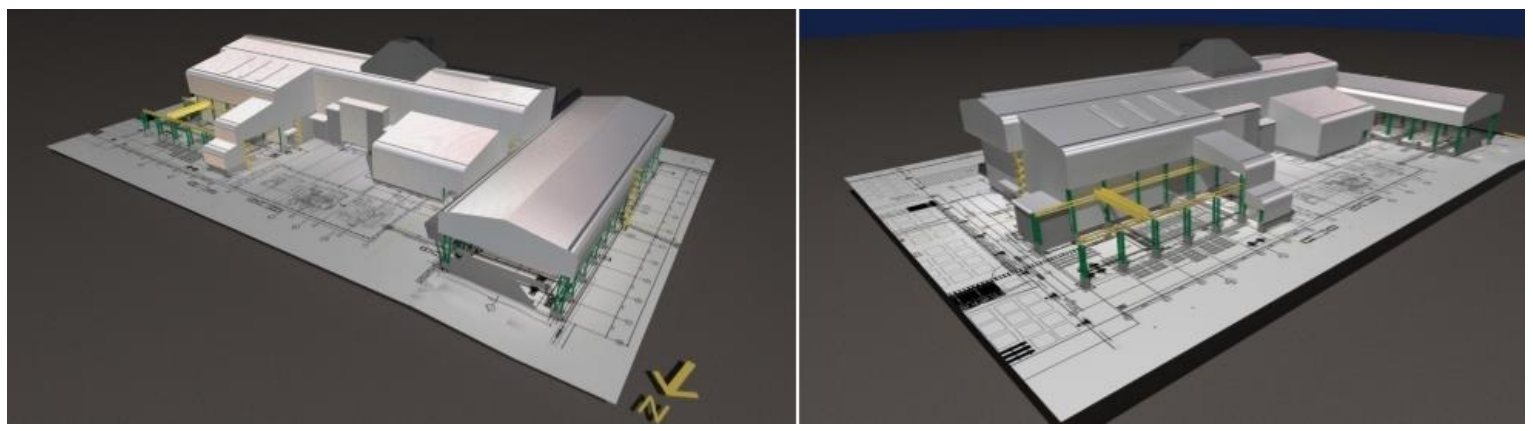

Figura 4 - Construção do prédio do Estaleiro - Projeto A

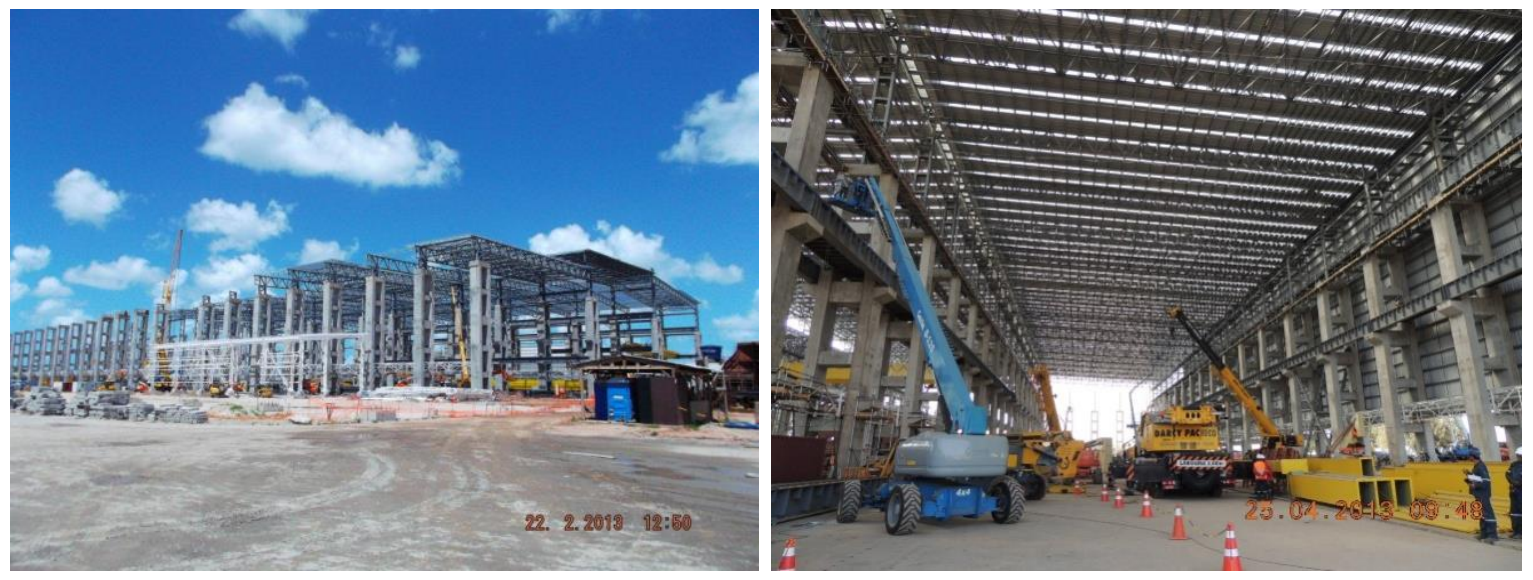

Figura 5 - Traçado de duplicação da Avenida - Projeto B

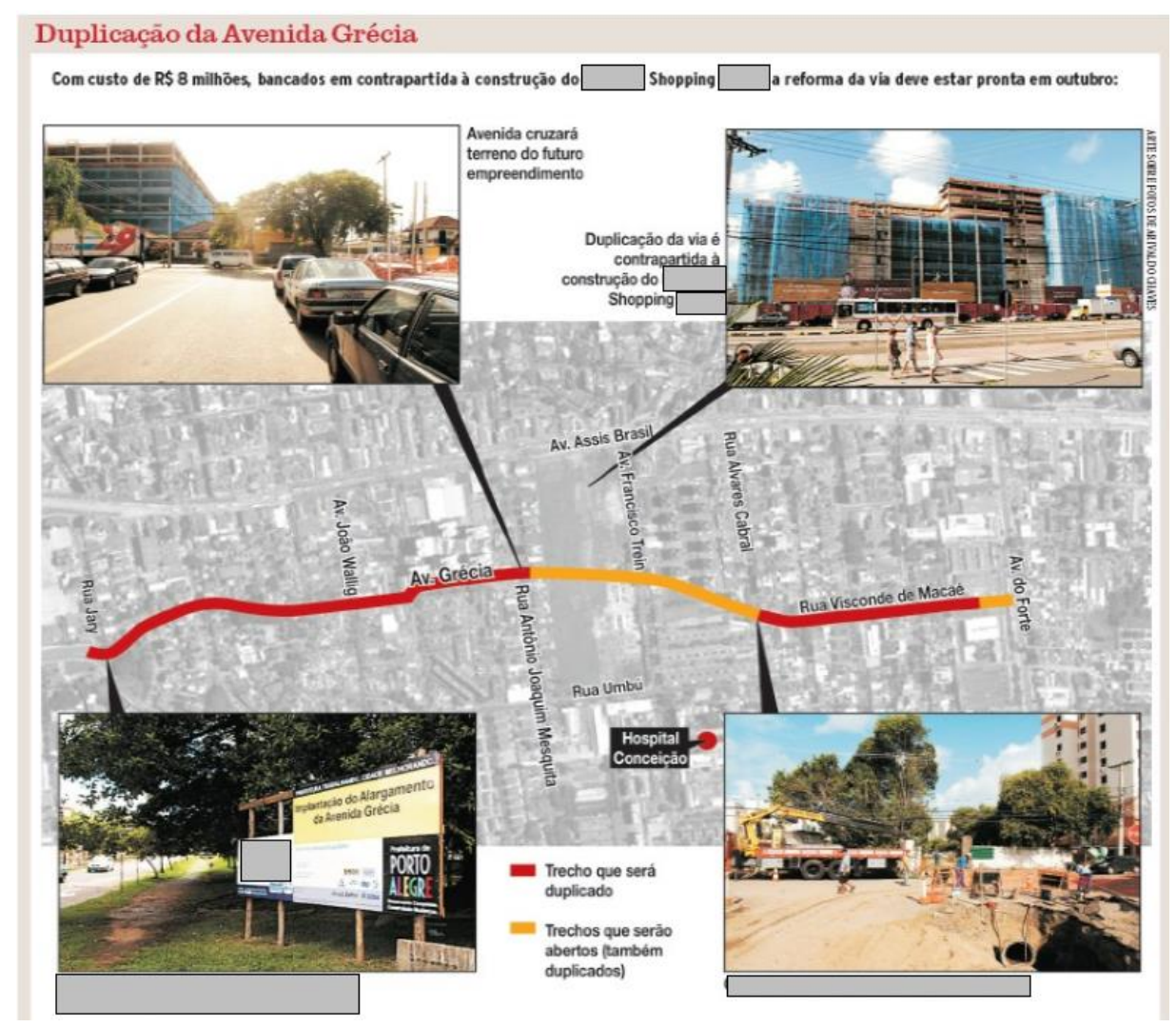




\section{Resultados}

\section{Caracterização do SGP da empresa ALFA}

A área denominada de Engenharia na empresa ALFA era responsável pela concepção, aprovação, implantação, avaliação e gestão do portfólio de projetos de manutenção ou ampliação da capacidade produtiva das unidades da empresa.

Para cada área a empresa ALFA possui um guia de suas políticas e diretrizes globais, o qual foi denominado de ALFA Business System (ABS). O ABS do processo de engenharia contém práticas da área de Engenharia e benchmarks, ${ }^{7}$ organizado com base nas práticas do PMI e seu respectivo manual de práticas de gerenciamento, denominado PMBOK. De uma forma geral, constatou-se que a Empresa ALFA utiliza um SGP típico da abordagem tradicional de gestão de projetos.

Ao longo do estudo, foram identificadas algumas dificuldades na gestão dos projetos da empresa ALFA, expressas principalmente pelo não atendimento às metas de cumprimento de escopo, prazo e orçamento dos projetos. $\mathrm{Na}$ unidade industrial estudada, os itens de controle do processo de Engenharia indicavam desvios médios de prazo e orçamento superiores a $15 \%$.

\section{Estudos realizados no Projeto BETA}

Para a realização dos processos de contratação dos EC1 e EC2, a coordenação do projeto, em conjunto com a área de Suprimentos, definiu os seguintes critérios para seleção das potenciais executoras:

(a) histórico de relacionamento;

(b) desempenho em obras anteriores;

(c) conhecimento e experiência em obras industriais específicas para o ramo da contratante;

(d) capacidade e disponibilidade de atendimento; e

(e) situação econômica e financeira.

No EC1 a lista de potenciais executoras para esse pacote contemplou quatro empresas do ramo de terraplenagem e pavimentação do Estado do Rio Grande do Sul. Após a realização da reunião de abertura, das quatro empreiteiras que participaram duas declinaram do processo alegando indisponibilidade para a realização desse tipo de trabalho. Dessa forma participaram do processo apenas duas (T1 e T2).

\footnotetext{
${ }^{7}$ São referências de desempenho em processos e operações.
}

A T1 participou da reunião de abertura demonstrando interesse e capacidade de atendimento, exceto para o item relativo ao desenvolvimento da engenharia, o qual correspondia à elaboração do design detalhado. Como não conseguiu estabelecer uma parceria com uma empresa de design, optou por não participar do processo após alguns dias.

Assim, o processo de contratação foi conduzido apenas com a participação da T2. Esta, por sua vez, trouxe importantes contribuições para o processo, evidenciados principalmente pela alocação de recursos humanos no estudo de soluções de design e na formatação das propostas técnica e comercial apresentadas. Para tanto, a T2 contratou um profissional com experiência em design geotécnico para auxiliá-la na busca de soluções mais racionais do ponto de vista econômico e técnico, trazendo para a discussão com a área de engenharia da Empresa ALFA uma série de sugestões e definições a serem tomadas em conjunto.

De forma sintética, buscou-se avaliar o NA das empresas participantes do processo de contratação do pacote de trabalho de movimentação de terra aos princípios de IPD, conforme apresentado na Tabela 1.

Nos processos de contratação do EC2 foram consideradas potenciais executoras localizadas no Estado do Rio Grande do Sul e também em outros estados. Nesse processo foram convidadas duas empresas construtoras ( $\mathrm{C} 1$ e $\mathrm{C} 2)$, as quais aceitaram o convite para participar do processo.

A C1 realizou estudo de soluções design aplicáveis ao projeto e discutiu com o cliente, procurando obter uma melhor relação de custo-benefício tanto para as instalações do projeto quanto para sua operação. A C1 contratou uma empresa de engenharia especializada no tipo de obra em questão para auxiliá-la na busca de soluções de design que atendessem aos requisitos do cliente e que fossem, ao mesmo tempo, competitivas comercialmente. Como resultado, a $\mathrm{C} 1$ apresentou uma proposta técnica com bom nível de detalhamento, adequada aos requisitos do cliente.

A C2 participou apenas da reunião de abertura, sem realizar contatos posteriores. Apesar de tentativas do cliente para aproximação e entendimento da situação do processo, a C2 enviou um orçamento após 30 dias sem nenhuma discussão técnica com a área de engenharia do cliente. Dessa forma, a proposta não atendeu às expectativas do cliente, tanto em relação a seu escopo quanto em relação às soluções de design consideradas.

94 Ioppi, V.; Formoso, C. T.; Isatto, E. L. 
Tabela 1 - Avaliação do nível de aderência das empresas participantes em relação aos aspectos e princípios de IPD - EC1

\begin{tabular}{|c|c|c|c|}
\hline \multirow[b]{2}{*}{ Princípios } & \multirow[b]{2}{*}{ Aspectos } & \multicolumn{2}{|c|}{$\begin{array}{l}\text { Nível de Aderência: } \\
\text { 1-baixo, 3-médio, 5-alto }\end{array}$} \\
\hline & & $\mathbf{T 1}$ & $\mathbf{T 2}$ \\
\hline \multirow{4}{*}{ Envolver agentes chave desde o início } & Colaboração entre as partes & 3 & 5 \\
\hline & Participação & 3 & 5 \\
\hline & Alinhamento & 1 & 5 \\
\hline & Engajamento & 3 & 5 \\
\hline \multirow{2}{*}{ Tomada de decisão compartilhada } & Soluções de design & - & 5 \\
\hline & Orçamento & - & 1 \\
\hline \multirow{3}{*}{ Inovação colaborativa } & Sugestões de design & - & 5 \\
\hline & Otimização do design & - & 5 \\
\hline & $\begin{array}{l}\text { Compartilhamento de } \\
\text { experiências }\end{array}$ & - & 5 \\
\hline
\end{tabular}

Em relação ao pacote de estruturas metálicas, foram convidadas três empresas (M1, M2 e M3). Da mesma forma que para o pacote de obras civis, a M1 participou apenas da reunião de abertura, não dando continuidade ao processo. Já a M2 participou de todas as etapas do processo, porém não trouxe contribuições relevantes em termos de soluções de design para o projeto.

$\mathrm{O}$ resultado mais significativo foi obtido com a M3, a qual teve como diferencial o fato de possuir uma equipe interna para desenvolvimento do design. Foram realizadas duas reuniões, em que foram levantados os requisitos do cliente, condicionantes, customizações necessárias, particularidades do processo industrial, detalhes sobre o plano de ataque da obra, etc. As soluções sugeridas foram apresentadas ao cliente e discutidas em conjunto, buscando uma melhor relação de custo-benefício, considerando, inclusive, o ciclo de vida do ativo e questões relacionadas a sua operação e manutenção. Por fim foi realizada uma reunião para apresentação das propostas técnica e comercial, da qual participaram representantes das áreas comercial e técnica da M3. O resultado final do trabalho superou as expectativas iniciais, principalmente em função do esforço da M3 na busca de soluções mais adequadas para o produto a ser desenvolvido.

De forma sintética, buscou-se avaliar o NA das empresas participantes do processo de contratação do pacote de trabalho das obras civis e estruturas metálicas aos princípios de IPD, conforme apresentado nas Tabelas 2 e 3 respectivamente.
Observa-se que a empresa M1 não foi avaliada porque declinou no início do processo.

Ao longo dos EC1 e EC2 verificou-se que o nível de contribuição das empresas convidadas para o processo de contratação estava relacionado ao ambiente criado pela empresa ALFA e à forma típica de atuação de cada participante. Além disso, empresas executoras que dispunham de equipe de design próprio ou empresa de design parceira trouxeram contribuições mais expressivas para os processos de contratação. Observou-se também que, devido ao fato de a empresa ALFA não divulgar o orçamento disponível para cada pacote de trabalho, não foi possível desenvolver um trabalho conjunto mais intenso em relação a esse aspecto, o qual resultou num NA baixo. É importante observar que, apesar de os estudos de caso não contemplarem todo o ciclo de vida do projeto, desde a concepção até a finalização dele, foi possível observar alguns aspectos relevantes relacionados ao comportamento das partes e ao contexto no qual os estudos foram realizados. De uma forma geral, nas empresas convidadas a participar dos processos foi possível distinguir três categorias de comportamentos distintos:

(a) recusa e agradecimento ao convite: $\mathrm{T} 1, \mathrm{~T} 3, \mathrm{~T} 4$ e M1;

(b) participação com pequeno envolvimento e contribuição: C2 e M2; e

(c) alto nível de colaboração e contribuição: T2, C1 e M3. 
Tabela 2 - Avaliação do nível de aderência das empresas participantes em relação aos aspectos e princípios de IPD - EC2 (obras civis)

\begin{tabular}{|c|c|c|c|}
\hline \multirow[b]{2}{*}{ Princípios } & \multirow[b]{2}{*}{ Aspectos } & \multicolumn{2}{|c|}{$\begin{array}{c}\text { Nível de Aderência: } \\
\text { 1-baixo, 3-médio, 5-alto }\end{array}$} \\
\hline & & C1 & $\mathbf{C 2}$ \\
\hline \multirow{4}{*}{ Envolver agentes chave desde o início } & Colaboração entre as partes & 5 & 3 \\
\hline & Participação & 5 & 1 \\
\hline & Alinhamento & 5 & 1 \\
\hline & Engajamento & 5 & 1 \\
\hline \multirow{2}{*}{ Tomada de decisão compartilhada } & Soluções de design & 5 & 1 \\
\hline & Orçamento & 1 & 1 \\
\hline \multirow{3}{*}{ Inovação colaborativa } & Sugestões de design & 5 & 1 \\
\hline & Otimização do design & 5 & 1 \\
\hline & $\begin{array}{l}\text { Compartilhamento de } \\
\text { experiências }\end{array}$ & 5 & 1 \\
\hline
\end{tabular}

Tabela 3 - Avaliação do nível de aderência das empresas participantes em relação aos aspectos e princípios de IPD - EC2 (estruturas metálicas)

\begin{tabular}{|c|c|c|c|}
\hline \multirow[b]{2}{*}{ Princípios } & \multirow[b]{2}{*}{ Aspectos } & \multicolumn{2}{|c|}{$\begin{array}{l}\text { Nível de Aderência: } \\
\text { 1-baixo, 3-médio, 5-alto }\end{array}$} \\
\hline & & M2 & M3 \\
\hline \multirow{4}{*}{ Envolver agentes chave desde o início } & Colaboração entre as partes & 3 & 5 \\
\hline & Participação & 3 & 5 \\
\hline & Alinhamento & 3 & 5 \\
\hline & Engajamento & 3 & 5 \\
\hline \multirow{2}{*}{ Tomada de decisão compartilhada } & Soluções de design & 3 & 5 \\
\hline & Orçamento & 1 & 1 \\
\hline \multirow{3}{*}{ Inovação colaborativa } & Sugestões de design & 1 & 5 \\
\hline & Otimização do design & 1 & 5 \\
\hline & $\begin{array}{l}\text { Compartilhamento de } \\
\text { experiências }\end{array}$ & 1 & 5 \\
\hline
\end{tabular}

\section{Informações obtidas nas entrevistas com os agentes-chave}

Em relação aos representantes dos clientes (contratantes), verificou-se que a empresa siderúrgica de CL1 adota uma forma de contratação mais tradicional, do tipo DBB. A empresa petrolífera de CL2, por sua vez, tem adotado formas de contratação do tipo EPC, porém inúmeras dificuldades foram relatadas em relação a essa forma, principalmente em função da dificuldade de a epcista ${ }^{8}$ coordenar as demais empresas subcontratadas e cumprir as restrições do projeto.

Por fim, o exemplo mais inovador entre os contratantes foi o SGP adotado pela empresa petroquímica de CL3, o qual consiste na utilização da abordagem Front-End Loading para avaliar o nível de refinamento do projeto nas etapas iniciais

\footnotetext{
${ }^{8}$ Designação atribuída à empresa contratada para execução de um projeto sob a forma de contratação do tipo EPC.
}

e ao mesmo tempo no estabelecimento de relações de parceria com executoras para sua participação ao longo de todo o ciclo de vida do projeto. A forma de contratação adotada para esse caso é uma variante da forma DBB, porém com a participação e envolvimento dos agentes-chave já na etapa de elaboração do design. Além disso, o instrumento contratual utilizado nessa abordagem é de preços unitários estabelecidos em contratos de dois anos de duração, que, aplicados aos quantitativos do design detalhado do projeto, se transformam num contrato de empreitada global a preço fixo. Segundo o entrevistado, eventuais modificações posteriores ao fechamento do contrato são avaliadas em conjunto entre as partes, e, sendo confirmada a alteração do design por necessidade do cliente, o contrato é ajustado conforme os preços unitários previstos nos contratos de referência. Segundo CL3, o ambiente existente na empresa devido à utilização desta abordagem está baseado nas relações de confiança, transparência e respeito entre os participantes dos projetos. Outro 
aspecto relevante é o fato de as executoras possuírem previsibilidade do volume de obras e montagens no ano, isso porque o cliente divulga para as empresas parceiras os orçamentos dos projetos previstos ao longo do ano.

Um aspecto interessante a ser analisado nas entrevistas é o fato de a empresa representante da indústria petroquímica utilizar uma forma de contratação similar à $\mathrm{DBB}$, típica da abordagem tradicional, de maneira que integre o cliente com as executoras, inclusive a empresa responsável pelo design. Parece haver indicações de que o estabelecimento prévio de relações comerciais, através dos contratos de preços unitários de referência, seja um diferencial, já que, nesse caso, o processo de contratação é dispensado. Além disso, a construção de um ambiente de confiança contribui para que as executoras participem da etapa de design, mesmo sem a previsão de uma remuneração específica para essa etapa, pois a execução da obra é relativamente previsível e declarada abertamente pelo cliente à executora.

Em contrapartida, o contexto dos projetos nas empresas siderúrgica (CL1) e petrolífera (CL2) não tem tido o mesmo desempenho que o da empresa petroquímica de CL3. Isso pode estar relacionado principalmente à forma de atuação dos clientes e executoras nesse contexto.

Em relação às entrevistas com as empresas executoras, E1 apontou uma série de questões relacionadas ao contexto atual dos projetos, destacando a forma de atuação e o comportamento dos clientes e executoras ao longo do projeto, as dificuldades existentes e suas consequências. Para E1, um dos motivos do insucesso de vários projetos está relacionado ao fato de o cliente não abrir a oportunidade para a potencial executora participar e contribuir, com sua experiência, na etapa de design. Além disso, segundo E2, um fator que agrava essa situação é a típica baixa qualidade técnica dos integrantes do time do projeto formado pelo cliente para a gestão do projeto. Para E2, essa deficiência técnica prejudica a análise e discussão de possíveis soluções de design em conjunto com a executora.

Além disso, E3 destacou a presença de grande nível de incertezas nos processos de contratação das obras, tipicamente com design de baixa qualidade, através dos quais os clientes buscam se resguardar e delegar o risco da execução às contratadas.

\section{Projeto A}

De uma forma geral, observou-se através das evidências analisadas que o Projeto A teve seu resultado prejudicado pelo SGP adotado pelo cliente. Esse projeto tinha um nível de complexidade relativamente alto, devido, principalmente, a incertezas relacionadas ao produto final (instalações), assim como devido ao número de agentes envolvidos e à interdependência entre as atividades de pacotes de trabalho distintos. Na linha de SGP adotado pelo cliente, o foco estava na execução e controle das atividades, e não nas interações necessárias e indispensáveis entre os participantes do projeto, a fim de obter as melhores soluções para o projeto, e não para as partes. Além disso, o fato de o cliente não ouvir as sugestões dos participantes, tomar decisões unilaterais e, de certa forma, autoritárias, sem medir os impactos para cada uma das partes, contribuiu para o baixo desempenho do projeto.

Como resultado dessa abordagem, além do não cumprimento do prazo e orçamento do projeto, a empresa responsável pelas obras civis teve desequilíbrio financeiro (prejuízo), o que motivou sua saída da obra antes da conclusão do pacote de trabalho. Já a empresa responsável pelas estruturas metálicas, apesar de ter concluído seu pacote de trabalho, não participou de outros processos de contratação com o mesmo cliente, devido aos prejuízos acumulados ao longo da obra.

\section{Projeto B}

A forma de contratação adotada neste projeto foi a do tipo DBB. O escopo de projeto era composto de itens de duas naturezas: de fácil previsibilidade, com menor nível de incertezas, e de difícil previsibilidade, devido, principalmente, às incertezas relacionadas à presença de interferências no subsolo e seu eventual impacto no projeto. Para os itens de menor complexidade foi estabelecido um contrato do tipo empreitada global a preço fixo. Já para os itens com maior nível de incertezas, foi proposta pela executora uma espécie de contrato híbrido, composto de uma tabela de preços unitários de referência associado a um contrato de alvos.

A iniciativa para adoção de uma forma e um instrumento de contratação diferenciados da abordagem tradicional foi da empresa executora no processo de contratação. $\mathrm{O}$ instrumento de contratação inicialmente proposto pelo cliente no processo de contratação era do tipo empreitada global a preço fixo para todos os itens do escopo. No entanto, devido à complexidade de parte do escopo, nenhuma das empresas convidadas apresentou proposta, restando apenas a sugestão da 
empresa que propôs essa forma alternativa, que acabou sendo aceita pelo cliente.

Em sua proposta comercial, a executora separou o orçamento em dois itens distintos, a saber:

(a) itens de preço fixo: itens que não sofreriam qualquer ajuste ao longo da execução, desde que mantido o escopo original; e

(b) itens sujeitos a medição: itens com maior incerteza, sendo proposto para estes o critério de pagamento por medição dos serviços executados, ou seja, medição in loco.

Para os itens sujeitos a medição, a proposta previa um teto, ou seja, um preço máximo a ser pago pelo cliente através das medições. Caso as medições ultrapassassem esse teto, o cliente não pagaria o excedente, desde que mantido o escopo original. Em contrapartida, caso as medições fossem inferiores ao valor estimado das medições, haveria o compartilhamento de $25 \%$ do saldo com a executora.

Verificou-se através da entrevista com E2 um elevado grau de satisfação de ambas as partes (da parte do cliente obtida indiretamente, conforme percepção e relato de E2) com a modalidade adotada no Projeto $\mathrm{B}$, e verificou-se o estabelecimento de uma relação de parceria entre as partes, evidenciada pela colaboração mútua para cumprimento do objeto do contrato dentro das restrições do projeto como um todo. Através de um esforço conjunto foi possível realizar o faturamento direto de insumos para a obra, que resultou em ganhos financeiros para o projeto.

\section{Principais barreiras e oportunidades identificadas}

Com base nos estudos e entrevistas realizados foram identificadas as seguintes barreiras à adoção de novas abordagens na gestão de projetos:

(a) modelo de SGP utilizados pelos clientes: via de regra, os modelos de SGP identificados na empresa ALFA e nas entrevistas são típicos da abordagem tradicional, com enfoque no planejamento, execução e controle das atividades, desconsiderando a natureza complexa dos projetos e a forma de organização (meios) necessária para o atingimento dos objetivos do projeto;

(b) formas e instrumentos de contratação praticados: em associação ao SGP vigente, as formas e instrumentos de contratação identificadas ao longo dos estudos também podem representar barreiras para a aplicação do SGP proposto neste trabalho, pois possuem foco na transação, e não na relação entre os agentes do projeto, dificultando assim a colaboração e o estabelecimento de uma relação do tipo ganha-ganha;

(c) forma de atuação dos clientes e executoras: verificou-se nos EC1 e EC2 que algumas potenciais executoras não tiveram interesse em participar do processo de contratação proposto devido ao fato de não ser baseado na forma tradicional (DBB). Algumas dessas empresas não estavam dispostas a desempenhar um novo papel de atuação e contribuição dentro do projeto em conjunto com o cliente, o qual correspondia a seu envolvimento prévio nas possíveis soluções de design. Pelo contrário, preferiram continuar atuando na forma tradicional; $\mathrm{e}$

(d) formação dos profissionais atuantes na gestão de projetos: ao longo dos estudos e entrevistas, verificou-se que a maior parte dos profissionais que atuam na gestão dos projetos, tanto por parte dos clientes quanto das executoras, possui uma formação técnica baseada nas práticas da abordagem tradicional de gestão de projetos composta, basicamente, do guia PMBOK.

Entretanto, foram identificadas algumas oportunidades de mudança no contexto estudado, apresentadas a seguir:

(a) considerar, apropriadamente, o contexto social e político no qual o projeto está inserido e por meio dessa análise, associada às características (hard ou soft) do projeto, estabelecer a melhor forma e instrumento de contratação aplicável ao contexto;

(b) estabelecer relações de parceria com os agentes-chave dos projetos, envolvendo-os desde o início do projeto, através da criação de espaços físicos ou virtuais, para a constante interação dos agentes;

(c) considerar a opinião e experiência dos participantes do projeto mediante o estabelecimento de um ambiente de respeito mútuo, transparência e de relações de confiança entre as partes;

(d) realizar a integração de processos internos, tanto nos clientes quanto nas executoras, relativos às áreas comercial e técnica (engenharia, fiscalização, execução);

(e) implementar práticas que adicionem valor ao design e compartilhem riscos e benefícios do projeto, tais como TVD, de forma conjunta com um processo de tomada de decisões compartilhado, com a participação dos agentes-chave do projeto;

(f) utilizar itens de controle e indicadores que representem o projeto como um todo, e não apenas o desempenho de suas partes; e 
(g) estabelecer metas comuns entre os participantes do projeto.

\section{Proposta de um modelo para implantação gradual de princípios de IPD e práticas de LPDS}

A concepção do modelo foi realizada a partir de alguns direcionadores, definidos com base nas informações obtidas nas etapas anteriores, a saber:

(a) considerar o SGP baseado no modelo de IPD, associado às práticas de LPDS - TVD e Set Based Design;

(b) estruturar o modelo em estágios, visando à implementação gradual do SGP proposto no trabalho; e

(c) definir o conteúdo e as características de cada estágio do modelo e sua forma de implementação de acordo com o contexto estudado.

Para a definição do número de estágios do modelo e seu respectivo conteúdo foram considerados os seguintes fatores:

(a) barreiras e oportunidades para aplicação da nova abordagem de gestão de projetos baseada em IPD e práticas de LPDS, conforme apresentado anteriormente;

(b) aplicação gradual dos princípios de IPD e práticas de LPDS, considerando o contexto atual de gestão de projetos e o tempo necessário para assimilação e consolidação do conteúdo de cada estágio; (c) mudança comportamental necessária aos agentes-chave ante a nova forma de condução dos projetos, observada durante a realização do estudo inicial na empresa ALFA; e

(d) necessidade de ajustes legais que suportem a abordagem proposta.

Com base nesses fatores, propôs-se a utilização de quatro estágios de implementação gradual dos conceitos de IPD e práticas de LPDS dentro da gestão de projetos de instalações industriais, conforme a Figura 6.

Com base no contexto dos estudos de caso e entrevistas foi desenvolvida uma proposta de aplicação gradativa dos princípios de IPD para cada estágio do modelo. Além disso, foi criada uma escala para identificar a presença e intensidade de cada elemento de IPD nos estágios do modelo, de 1 a 5 , em que 1 representa a presença do elemento, porém de baixa intensidade ainda, 3 corresponde à presença e intensidade média, e 5 alta, conforme apresentado no Quadro 3 .

Destaca-se que a definição do conteúdo do estágio 1 levou em consideração as práticas atuais de gestão de projetos observadas no SGP da empresa ALFA, EC1 e EC2, além das informações obtidas nas entrevistas com agentes-chave. Nos estágios 2 e 3 foram propostas práticas que visam à transição do contexto do estágio 1 para o patamar do estágio 4, o qual contemplou práticas ainda pouco utilizadas e reportadas na literatura, tais como $\mathrm{Set}$ Based Design e o próprio SGP baseado em IPD.

Figura 6 - Modelo de implantação gradual do SGP proposto - 4 estágios

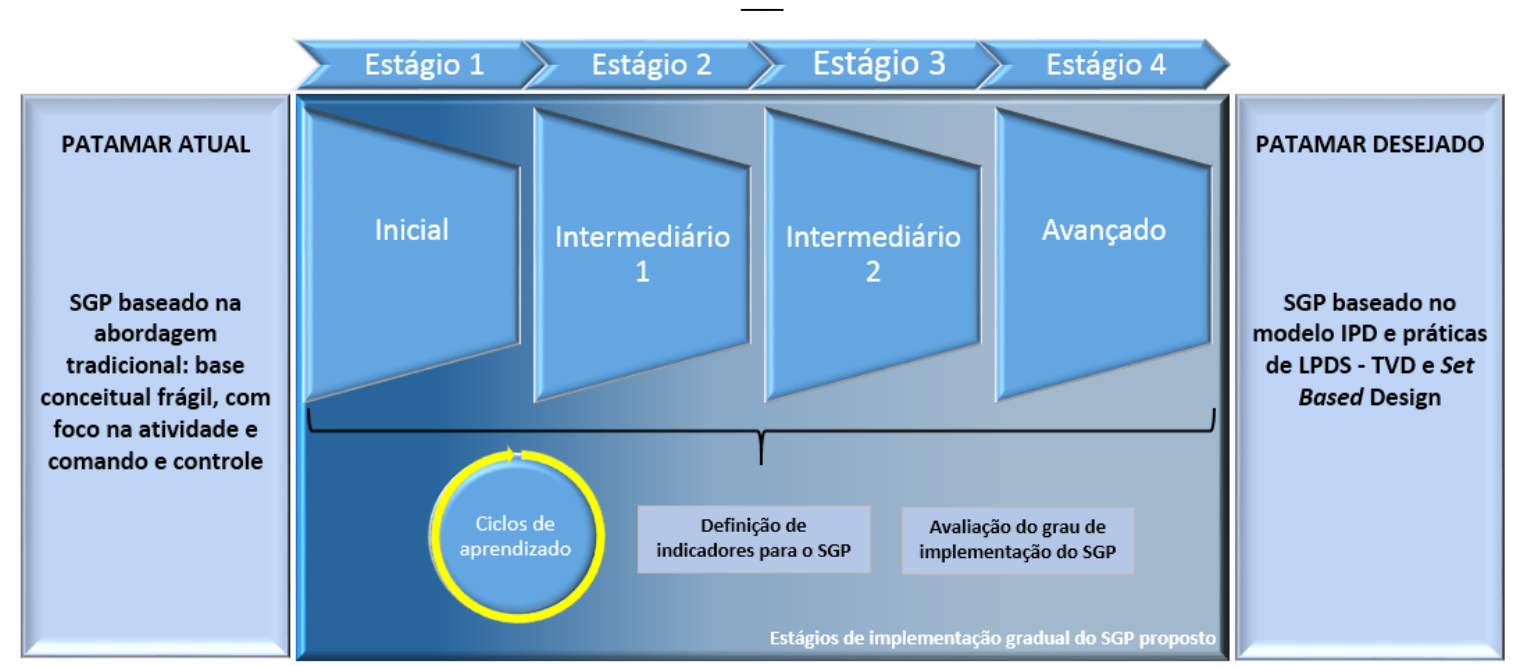




\section{Quadro 3 - Presença e intensidade dos princípios de IPD propostos para cada estágio do modelo}

\begin{tabular}{|c|c|c|c|c|c|c|}
\hline & & & $\begin{array}{r}\text { F } \\
\text { Pres } \\
\text { 1- be }\end{array}$ & $\begin{array}{l}\text { ípios de } \\
\text { a e Inte } \\
\text { 3-méd }\end{array}$ & $\begin{array}{l}\text { D } \\
\text { dade } \\
\text {-alta }\end{array}$ & \\
\hline & & 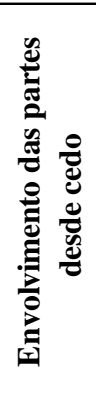 & 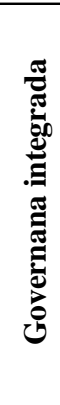 & 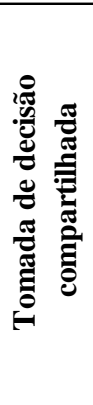 & 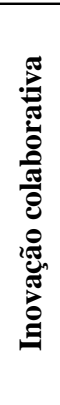 & 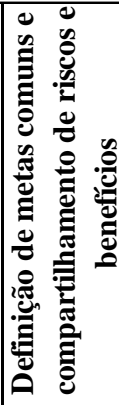 \\
\hline \multirow{4}{*}{$\begin{array}{l}\text { Presença e Intensidade } \\
\text { proposta no modelo de } \\
\text { implantação gradual }\end{array}$} & Estágio 1 & 3 & 1 & 1 & 3 & 1 \\
\hline & Estágio 2 & 3 & 1 & 3 & 3 & 3 \\
\hline & Estágio 3 & 5 & 3 & 3 & 5 & 5 \\
\hline & Estágio 4 & 5 & 5 & 5 & 5 & 5 \\
\hline
\end{tabular}

O estágio 1 do modelo tem como principal objetivo iniciar a implementação de uma abordagem mais colaborativa entre as partes, através do envolvimento dos agentes-chave já na etapa de design. Para tanto, sugere a utilização de uma matriz multicriterial para a escolha dos participantes do projeto, na qual podem ser definidos critérios para a seleção de potenciais executoras e projetistas, tais como histórico de relacionamento e conhecimento e experiência na área do projeto. Nesse mesmo sentido propôs-se a adoção de um mecanismo para remuneração dos agentes-chave durante as etapas de concepção do projeto e design.

Esse estágio também prevê o estabelecimento de um processo de tomada de decisão compartilhado entre os agentes-chave, sendo a definição desse processo realizada de forma conjunta entre as partes, podendo ser representado através de um diagrama de tomada de decisão, no qual conste o fluxo desse processo.

O estágio 2, por sua vez, compreende o fortalecimento das ações e práticas adotadas no estágio 1 e prevê, além disso, a implementação de uma governança integrada, com a participação dos agentes-chave, através do estabelecimento do core group do projeto. Para tanto, sugere a criação de um organograma funcional, a fim de estabelecer as atribuições de cada componente do core group.

Além disso, o estágio 2 prevê também a utilização das práticas de TC como forma de encontrar melhores soluções para o design e, ao mesmo tempo, atender aos requisitos de desempenho do produto final e ao orçamento estabelecido para o projeto. Associado a isso, pode contribuir para o compartilhamento dos riscos e benefícios do projeto, expresso através da elaboração conjunta de uma matriz de riscos do projeto.

No estágio 3 é proposta a consolidação do modelo IPD como o SGP, tendo como características as práticas adotadas nos estágios anteriores, acrescidas pela utilização de TVD (tomada de decisão baseada no valor, e não apenas no custo) e pela adoção de contratos relacionais (também conhecidos como multipartes). Nesse estágio, os agentes-chave são envolvidos desde a concepção do projeto, e, para tanto, há mecanismos definidos para remuneração das partes no caso de o projeto não ter continuidade.

Por último, o estágio 4 tem por objetivo consolidar e padronizar os processos do SGP com base no modelo de IPD. Para tanto é proposta a elaboração de um mapa do processo do SGP. Além disso, TVD e Set Based Design representam importantes práticas que embasam a tomada de decisão do projeto, reduzem retrabalhos durante a execução e contribuem para a adoção de soluções que agregam valor ao projeto e seu produto final. Este estágio também prevê a criação de indicadores relacionados ao novo modelo implantado.

De forma comum a todos os estágios, o modelo prevê a realização de ciclos de aprendizado durante e ao final da implementação de cada estágio.

Com o objetivo de avaliar o grau de implementação do SGP proposto em cada estágio do modelo, utilizou-se como referência o Índice de Boas Práticas (IBP) proposto por Bernardes 
(2001), cujo objetivo era avaliar o grau de implementação de sistemas de planejamento e controle da produção baseados no Last Planner. Para tanto o referido autor propôs 14 práticas como referência e, através da atribuição de notas a essas práticas, estabeleceu um valor de eficácia da implementação do sistema, medido em porcentagem. Da mesma forma, a ferramenta de avaliação proposta neste estudo considerou o desdobramento dos princípios de IPD em práticas para cada estágio, para as quais foram atribuídas notas da seguinte forma:

(a) peso 1 (um) para práticas utilizadas de maneira integral;

(b) peso 0,5 para práticas utilizadas de maneira parcial; e

(c) peso 0 (zero) para práticas não utilizadas.
No presente trabalho, este índice foi denominado de índice de boas práticas de gestão do projeto (IBPGP).

O cálculo do IBPGP pode ser realizado de acordo com a Equação 1:

IBPGP $=\frac{\sum \text { Notas das práticas }}{\text { Número de práticas }}$.

As práticas a serem avaliadas para a determinação do IBPGP, em cada estágio do modelo, são apresentadas no Quadro 4.

Destaca-se que além das práticas específicas de cada estágio do modelo foram definidas práticas comuns a todos os estágios do modelo, as quais também devem fazer parte da avaliação do IBPGP em cada estágio.

\section{Quadro 4 - Práticas a serem avaliadas para a determinação do IBPGP}

\begin{tabular}{|c|c|c|}
\hline & Prática & Descrição \\
\hline \multirow{5}{*}{ Estágio 1} & 1 & Envolvimento dos agentes chave na fase de elaboração do design \\
\hline & 2 & Tomada de decisões participativas em relação às definições do design \\
\hline & 3 & $\begin{array}{l}\text { Previsão de remuneração dos agentes chave envolvidos no caso de o projeto não } \\
\text { prosseguir }\end{array}$ \\
\hline & 4 & $\begin{array}{l}\text { Seleção das empresas parceiras baseada em critérios preestabelecidos numa matriz } \\
\text { multicriterial }\end{array}$ \\
\hline & 5 & Divulgação do orçamento do projeto \\
\hline \multirow{5}{*}{ Estágio 2} & 6 & O cliente é um agente ativo (participativo) e permanente na equipe do projeto \\
\hline & 7 & Tomada de decisões relativas ao projeto realizada por meio de um core group \\
\hline & 8 & Definição conjunta do custo-meta do projeto \\
\hline & 9 & Compartilhamento dos resultados do projeto \\
\hline & 10 & Elaboração conjunta de um plano de riscos \\
\hline \multirow{3}{*}{ Estágio 3} & 11 & $\begin{array}{l}\text { Utilização de contratos relacionais, com mecanismos de compartilhamento de riscos } \\
\text { e benefícios }\end{array}$ \\
\hline & 12 & Utilização de espaços físicos e virtuais para interação dos agentes \\
\hline & 13 & Definição conjunta das metas do projeto \\
\hline \multirow{5}{*}{ Estágio 4} & 14 & Padronização do processo do SGP \\
\hline & 15 & Análise de múltiplas alternativas simultâneas para a definição das soluções de design \\
\hline & 16 & $\begin{array}{l}\text { Tomada de decisão participativa baseada no valor agregado ao projeto e seu } \\
\text { produto }\end{array}$ \\
\hline & 17 & Co-locação dos agentes (big room) \\
\hline & 18 & $\begin{array}{l}\text { Estimativa de custo e orçamento é atualizado continuamente com a participação dos } \\
\text { agentes chave }\end{array}$ \\
\hline \multirow{4}{*}{ Comum } & 19 & Rotinização de reuniões para discussão e registro de aprendizados \\
\hline & 20 & Realização de ações corretivas a partir dos aprendizados \\
\hline & 21 & Rotinização de reuniões de acompanhamento do projeto \\
\hline & 22 & Utilização de um indicador para avaliar o SGP implantado \\
\hline
\end{tabular}




\section{Conclusões}

Os SGP vigentes no contexto dos projetos da indústria de base são predominantemente relativos à abordagem tradicional de gestão de projetos. Como consequência disso os projetos de natureza complexa, tais como os de instalações da indústria de base, não têm atingido plenamente seus objetivos. Além disso, observaram-se nos estudos realizados inúmeras dificuldades para atendimento às restrições dos projetos, relativas ao orçamento e prazo, associado a um ambiente litigioso entre os agentes dos projetos. Alternativamente a esse cenário o modelo proposto neste estudo busca gradativamente contribuir para a criação de um ambiente de maior colaboração entre as partes, com o estabelecimento de relações do tipo ganhaganha e com foco na redução de perdas nos processos. Verificou-se nos estudos e entrevistas que algumas iniciativas nessa mesma linha têm apresentado bons resultados, tais como nas empresas petroquímica e de terraplenagem e pavimentação analisadas. No entanto, o sucesso na implantação do modelo depende de um contexto favorável para sua aplicação, expresso através da disposição dos agentes em colaborar mutuamente e estabelecer relações de confiança, respeito e transparência. Tanto no EC1 como no EC2 observou-se que um dos fatores que dificultaram a obtenção de propostas mais ajustadas às necessidades do cliente foi o fato de a empresa ALFA não informar às empresas participantes do processo o orçamento disponível para cada pacote de trabalho, o que resultou num NA baixo no aspecto orçamento. Associado ao contexto favorável, torna-se indispensável a disposição dos agentes-chave em se adaptar a essa nova forma de organização para execução do projeto, a qual demanda modificações na típica forma de atuação e comportamento das partes.

Com o objetivo de dar continuidade ao estudo, sugere-se a realização de teste do modelo proposto, a incorporação de boas práticas na lista proposta neste estudo para avaliação do IBPGP, o aprofundamento do conhecimento dos potenciais benefícios e impactos devidos à utilização da prática Set Based Design no contexto dos projetos de instalações industriais, a avaliação da incorporação do sistema de controle da produção Last Planner no escopo do modelo e o estudo de modelos de contrato relacional para o contexto legal brasileiro. Além disso, sugere-se a realização de discussões sobre os indutores de inovações gerenciais e mudanças organizacionais necessárias no contexto dos projetos da construção, avaliando seus respectivos riscos.

\section{Referências}

AMERICAN INSTITUTE OF ARCHITECTS. Integrated Project Delivery: a guide. 2007.

Disponível em:

<http://www.aia.org/groups/aia/documents/pdf/aia b083423.pdf>. Acesso em: 12 nov. 2012.

ATKINSON, R.; CRAWFORD, L.; WARD, S. Fundamental Uncertainties in Projects and the Scope of Project Management. International Journal of Project Management, v. 24, n. 8, p. 687-698, 2006.

AUSTROADS. Building and Construction Procurement Guide: principles and options. Sidney, A4, p. 56, 2014. Disponível em: <http://www.apcc.gov.au/ALLAPCC/Building\%2 0and\%20Construction\%20Procurement $\% 20$ Guide. pdf>. Acesso em: 23 dez. 2014.

BALLARD, G. The Lean Project Delivery System: an update. Lean Construction Journal, p. 1-19, 2008.

BALLARD, G. Should Project Budgets be Based on Worth or Cost? In: INTERNATIONAL CONFERENCE OF THE INTERNATIONAL GROUP FOR LEAN CONSTRUCTION, 20., San Diego, 2012. Proceedings... San Diego, 2012.

BAPTISTA, L. O. et al. Contratos de Obras e Gestão de Pleitos. Newsletter, ano 5, n. 60, abr. 2010. Disponível em:

<http://www.baptista.com.br/news/Texto.aspx?Te xto $=217>$. Acesso em: 25 nov. 2014.

BERNARDES, M. M. S. Desenvolvimento de Um Modelo de Planejamento e Controle da Produção para Micro e Pequenas Empresas da Construção. Porto Alegre, 2001. Tese (Doutorado em Engenharia Civil) - Curso de Pós-Graduação em Engenharia Civil, Universidade Federal do Rio Grande do Sul, Porto Alegre, 2001.

CHAN, A. P.; CHAN, D. W.; YEUNG, J. F. Relational Contracting for Construction Excellence: principles, practices and case studies. New York: Spon Press, 2010.

COOPER, R. When Lean Enterprise Colide: competing through confrontation. Boston: Harward Business School Press, 1995.

COOPER, R.; SLAGMULDER, R. Target Costing and Value Engineering. Portland: Productivity Press, 1997.

DELOITTE. Capital Projects Advisory: how deloitte can help to reduce claims and costs overruns? 2013. [Slides]. Material de uso interna da empresa Alfa. 
DINSMORE, P.; MUTTI, A.; ROCHA, L. Contratos de aliança: Solução para Projetos Brasileiros? Mundo Project Management, [s.i], n., p.31-35, set. 2011. Mensal.

GHASSEMI, R.; BECERIK-GERBER, B. Transitioning to Integrated Project Delivery: Potential Barriers and Lessons Learned. Lean Construction Journal. p. 32-52. 2011.

HOWELL, G. A.; MESA, H.; ALARCÓN, L. F. Characterization of Lean Project Delivery. In: INTERNATIONAL CONFERENCE OF THE INTERNATIONAL GROUP FOR LEAN CONSTRUCTION, 21., Fortaleza, 2013. Proceedings..., Fortaleza, 2013.

JOHANNSEN, H. K. Design-Build Project Delivery in Practice: some practical issues. Project Management Conference, Yellowknife, 2013. Disponível em: <http://www.pws.gov.nt.ca/pdf/PMC/DesignBuild_Project\%20Delivery\%20in\%20Practice\%20 -\%20Some\%20Practical\%20Issues.pdf>. Acesso em: 20 dez. 2014.

KOSKELA, L; HOWELL, G. The Underlying Theory of Project Management is Obsolete. In: PMI RESEARCH CONFERENCE, Seattle, 2002. Proceedings... Seattle, 2002.

KOSKELA, L. J.; BALLARD, G. Should Project Management Be Based on Theories of Economic or Production? Building Research \& Information, v. 32, n. 2, p. 154-163, 2006.

RICARDINO, R. Administração de Contrato em Projetos de Construção Pesada no Brasil: um estudo da interface com o processo de análise do risco. São Paulo, 2007. 172 f. Dissertação (Mestrado em Engenharia Civil) - Escola Politécnica, Universidade de São Paulo, São Paulo, 2007.

ROSS, J.; PCI ALLIANCE SERVICES. Alliance Contracting in Australia: a brief introducion. 2009. Disponível em: <http://www.pcigroup.com.au/wpcontent/uploads/2013/02/2009_09_07_AlliancingRoss_intro_B.pdf>. Acesso em: 19 mar. 2014.
SAKAL, M. W. Project Alliancing: a relational contracting mechanism for dynamic projects. Lean Construction Journal, v. 2, n. 1, 2005.

SCHMITT, G. Contracting in the Global Market Place. In: INTERNATIONAL FEDERATION OF SURVEYORS CONGRESS, 23., Munich, 2006. Proceedings... Munich, 2006.

SMITH, R. E.; MOSSMAN, A.; EMMITT, S. Editorial: Lean and Integrated Project Delivery Special Issue. Lean Construction Journal, p. 116, 2011. Disponível em: <http://www.leanconstruction.org/media/docs/lcj/2 011/LCJ_11_sp1.pdf>. Acesso em: 10 mar. 2014.

THOMSEN, C. et al. Managing Integrated Project Delivery. CMAA, US, 2009. Disponível em:

<http://cmaanet.org/files/shared/ng_Integrated_Pro ject_Delivery_11-19-09_2_.pdf >. Acesso em: 2 jul. 2013.

WARD, A. C.; LIKER, J. K.; SOBEK, D. K. Toyota's Principles of Set-Based Concurrent Engineering. Sloan Management Review, Cambridge, v. 40, n. 2, winter, 1999.

WILLIAMS, T. Modelling Complex Projects. Chichester: John Wiley \& Sons, 2002.

WILLIAMSON, O. E. The Economic Institutions of capitalism. New York: The Free Press, 1985.

WINTER, M. et al. Directions for Future Research in Project Management: the main findings of UK government-funded research network. International Journal of Project Management, v. 24, n.8, p. 638-649, 2006.

YU, A. S. O.; CAMARGO JÚNIOR, A. S. C. Engenharia Simultânea: uma comparação entre as estratégias set-based e point-based. Revista da Administração, São Paulo, v. 42, n. 3, p. 326-337, jul./set. 2007. 


\section{Vinícius loppi}

Gerdau Riograndense | Av. Borges de Medeiros, 650, São Jorge | Sapucaia do Sul - RS - Brasil | CEP 93212-110 | Tel.: (51) 3450-7662 | E-mail: vioppi@gmail.com

\section{Carlos Torres Formoso}

Núcleo Orientado para a Inovação da Edificação, Programa de Pós-Graduação Em Engenharia Civil | Universidade Federal do Rio Grande do Sul | Av. Osvaldo Aranha, 99, $3^{\circ}$ andar, Bom Fim | Porto Alegre - RS - Brasil | CEP 90035-190 | Tel.: (51) 3308-3518 | E-mail:

formoso@ufrgs.br

\section{Eduardo Luis Isatto}

Departamento de Engenharia Civil, Escola de Engenharia | Universidade Federal do Rio Grande do Sul | Av. Osvaldo Aranha, 99, Prédio Castelinho, Centro | Porto Alegre - RS - Brasil | CEP 90035-190 | Tel.: (51) 3308-3959 | E-mail: isatto@ufrgs.br

\section{Revista Ambiente Construído}

Associação Nacional de Tecnologia do Ambiente Construído

Av. Osvaldo Aranha, $99-3^{\circ}$ andar, Centro

Porto Alegre - RS - Brasil

CEP 90035-190

Telefone: +55 (51) 3308-4084

Fax: +55 (51) 3308-4054

www.seer.ufrgs.br/ambienteconstruido

E-mail: ambienteconstruido@ufrgs.br

104 Ioppi, V.; Formoso, C. T.; Isatto, E. L. 